\title{
Clinical, Socioeconomic, and Psychosocial Factors Associated with Blood Pressure Control and Adherence: Results from a Multidisciplinary Cardiovascular National Program Providing Universal Coverage in a Developing Country
}

\author{
Daniela Sandoval (D), $^{1,2}$ Carolina Nazzal, ${ }^{3}$ and Tomás Romero ${ }^{4}{ }^{4,5}$ \\ ${ }^{1}$ Department of Primary Care \& Health Family, Faculty of Medicine, University of Chile, Santiago, Chile \\ ${ }^{2}$ Department of Physical Therapy, Faculty of Medicine, University of Chile, Santiago, Chile \\ ${ }^{3}$ School of Public Heath, Faculty of Medicine, University of Chile, Santiago, Chile \\ ${ }^{4}$ School of Medicine, University of California, San Diego, CA, USA \\ ${ }^{5}$ Institutional Review Board, Sharp Health Care, San Diego, CA, USA \\ Correspondence should be addressed to Tomás Romero; tromero560@aol.com
}

Received 28 November 2017; Accepted 17 June 2018; Published 9 July 2018

Academic Editor: Markus P. Schlaich

\begin{abstract}
Copyright (C) 2018 Daniela Sandoval et al. This is an open access article distributed under the Creative Commons Attribution License, which permits unrestricted use, distribution, and reproduction in any medium, provided the original work is properly cited.
\end{abstract}

\begin{abstract}
Background. Limited information exists on blood pressure (BP) control factors and adherence to antihypertensive drug therapy (Rx) in developing countries. Methods. Cross-sectional study in randomly selected 992 hypertensive patients under a Chilean national comprehensive Cardiovascular Health Program (CVHP). Association of education, income, diabetes, obesity, physical activity, psychosocial characteristics, smoking, and alcohol abuse with BP control and adherence were evaluated by multivariate logistic regression. Results. BP control $(<140 / 90 \mathrm{mmHg})$ was achieved in $63.1 \%$ of patients, with $38.4 \%$ adherent to Rx. Uncontrolled BP significantly associated with male sex (OR: 1.73 [95\% CI 1.35-2.22]), low family income, high emotional-stress-depression score, body mass index, no adherence (OR: 1.83 [95\% CI 1.44 - 2.32]), multiple Rx, baseline systolic BP value, and sedentary life style. Males (OR: 1.54 [95\% CI 1.23 - 1.93]), low family income, high emotional stress-depression score (OR: 2.15 [95\% CI 1.68 - 2.76]), low social support, and uncontrolled BP (OR: 1.52 [95\% CI 1.22-1.90]) associated with no adherence. Conclusions. Comparable BP control (63.1\%) to higher-income societies was observed. Uncontrolled BP associated significantly to no adherence and both to male sex, socioeconomic, and psychosocial factors. Global low adherence (38.4\%) and improved BP control and adherence in diabetics were noted.
\end{abstract}

\section{Introduction}

Unsatisfactory BP control according to accepted guidelines is a persistent worldwide problem in the hypertensive population $[1,2]$. In high-income countries approximately $55 \%$ of patients with access to antihypertensive drug therapy $(\mathrm{Rx})$ do not reach a satisfactory $\mathrm{BP}$ control $(<140 / 90 \mathrm{mmHg})$, and lack of adherence to treatment $(\mathrm{Rx})$ is considered an important factor [3-5]. A World Health Organization sponsored study (SAGE) that included 47,443 adults from six middle-income countries (China, Ghana, India, Russia, Mexico, and South Africa) sampled between 2007 and 2010 documented that more than $90 \%$ of the hypertensive patients had uncontrolled $\mathrm{BP}$, and insurance as well as income status emerged as significant correlates to diagnosis and treatment [6]. Unfavorable socioeconomic and psychosocial conditions have been frequently mentioned as barriers for BP control and adherence to $\mathrm{Rx}$, of particular relevance in developing countries and/or social groups with limited access to health resources [6-10].

Chile is a developing country undergoing an accelerated process of socioeconomic transition and classified along with Uruguay in the high-income bracket in South America yet with one of the highest coefficients of social inequality (GINI Index 50.5) [11]. 
Approximately $75 \%$ of the Chilean population receives primary medical care in government sponsored primary care centers financed through FONASA (Fondo Nacional de Salud, National Health Fund) a legally mandated $7 \%$ tax on wages and from government subsidies (64\% of total)[12]. Approximately $20 \%$ of the populations are affiliated to private or institutional medical services, with a different financing (private) system. FONASA guarantees coverage free of copayments for medical care at government sponsored primary care centers including approved medications for eighty medical conditions through a Health Care Policy Act approved in 2005 (Garantías Explícitas de Salud, GES, or Explicit Health Warranties) [13].

In 2002 a Cardiovascular Health Program (CVHP) (Programa de Salud Cardiovascular) was started in Chile implemented at the government sponsored primary care centers as part of the National Health Program aimed at reducing cardiovascular morbidity, the mayor cause of death and the third cause of disability in Chile today [10]. The increasing rates of obesity and diabetes in the Chilean hypertensive population were major determinants of this program $[10,14]$. In the CVHP patients are provided access to treatment and screening for cardiovascular risk factors plus a multidisciplinary approach to modify unfavorable life style and habits free of copayments. It is estimated that approximately 500,000 hypertensive patients are followed through the CVHP in the Metropolitan region of Santiago [14]. Previous results from hypertensive patients evaluated between 2009 and 2010 enrolled in the CVHP since 2006 have been published [10]. The objective of the present study is to evaluate the association of socioeconomic and psychosocial factors, life style behavior, and adherence to $\mathrm{Rx}$ with $\mathrm{BP}$ control, not analyzed in previous studies, in 992 patients from four different primary care centers with at least one year attending the CVHP.

\section{Methods}

2.1. Study Population. The study was conducted in four government subsidized primary care centers in the Metropolitan region of Santiago, Chile. Patients at the primary care centers with $\mathrm{BP} \geq 140 / 90 \mathrm{mmHg}$ are referred to the CVHP and screened for associated cardiovascular risk factors (diabetes, dyslipidemias, and renal failure). Approximately every 3 months they were followed by a team of primary care physicians, dietitians, and trained medical assistants providing clinical evaluation, assessment of life style habits, and counseling for modification of unhealthy behavior.

Hypertensive patients followed in the selected centers were considered for inclusion in the study; a randomly selected sample of 992 was obtained from 14,363 patients under care in these centers. Data was collected between 2011 and 2014. The sampling size was estimated for an expected prevalence of $\mathrm{BP}<140 / 90 \mathrm{mmHg}$ of $50 \%$, with $95 \%$ of confidence, estimated error of 5\%, and design effect of 2.5. None of these patients have been part of a previous study completed between 2009 and 2010 in different primary care centers in the Santiago Metropolitan Region.

Inclusion criteria considered patients between 30 and 64 years of age, who had completed at least a year in the CVHP receiving antihypertensive drug therapy at the time of recruitment. Patients with significant disabilities (bedridden, mentally incompetent, and wheel chair users), pregnant women, or with frequent unjustified missed appointments were excluded $(n=17)$. Excluded patients were replaced according to a random procedure using the EPI-Info software.

Patients were invited to participate in the study by trained medical assistants working at the primary care centers. It was explained to patients that their participation only implied an agreement to authorize the information collected to be analyzed and eventually published without compromising their privacy and ensuring confidentiality. If initial hesitation from patients to participate was encountered, follow-up of contacts was carried out to address all their concerns. Finally, all patients initially invited consented to participate (Figure 1).

Patients with documented associated cardiovascular comorbidities (coronary heart disease, valvular heart disease, and rhythm disturbances) or requiring hemodialysis were referred to secondary (specialist) level of care before randomization and therefore not included in the study (3.17\% of the eligible population, 14,363 patients).

2.2. Variables. 513 patients were recruited between August 2011 and June 2012 and 479 between August 2013 and June 2014. At the time of recruitment demographic, education, income, clinical, weight, and height data was obtained and questionnaires previously validated in compatible Chilean populations regarding adherence, psychosocial variables, and life style habits (smoking, use of alcohol, and physical activity) were filled at the clinic or within a week by the patients who preferred to do it at home; assistance to clarify questions was always available as requested. The blood chemistry values used in the analysis of the study were the most recent ones available at the time of recruitment. Data analysis was completed on $07 / 2016$.

Trained medical assistants recorded BP values at each one of the patient's visits after three successive measurements with the patient sitting at least for 5 minutes using mercury sphygmomanometers and recording the average of the two last measurements. The $\mathrm{BP}$ value at the time of referral to the CVHP was interpreted as the baseline $\mathrm{BP}$ and the average of BP measurements recorded during the last year of followup preceding the time of recruitment in the study was considered the final $\mathrm{BP}$ results. The average time of care in the CVHP was $7.5 \pm 4.6$ years. Presence of diabetes and other comorbidities was established by clinical diagnosis and/or therapies prescribed. Blood chemistries that included fasting blood glucose, total and HDL cholesterol, and $\mathrm{HbA1}$ in diabetics were measured using standard techniques. Weight was measured using a calibrated digital scale with patients in underwear and barefoot. Body mass index (BMI) was calculated dividing the weight in kilograms by the square of height in meters. All the antihypertensive medications in use at the time of recruitment were recorded.

Family income was defined as the ratio between the total monthly family income and total number of members in the family. Low family income was defined as $<$ than the lower quartile of monthly income for individuals (< US\$ 80/per 


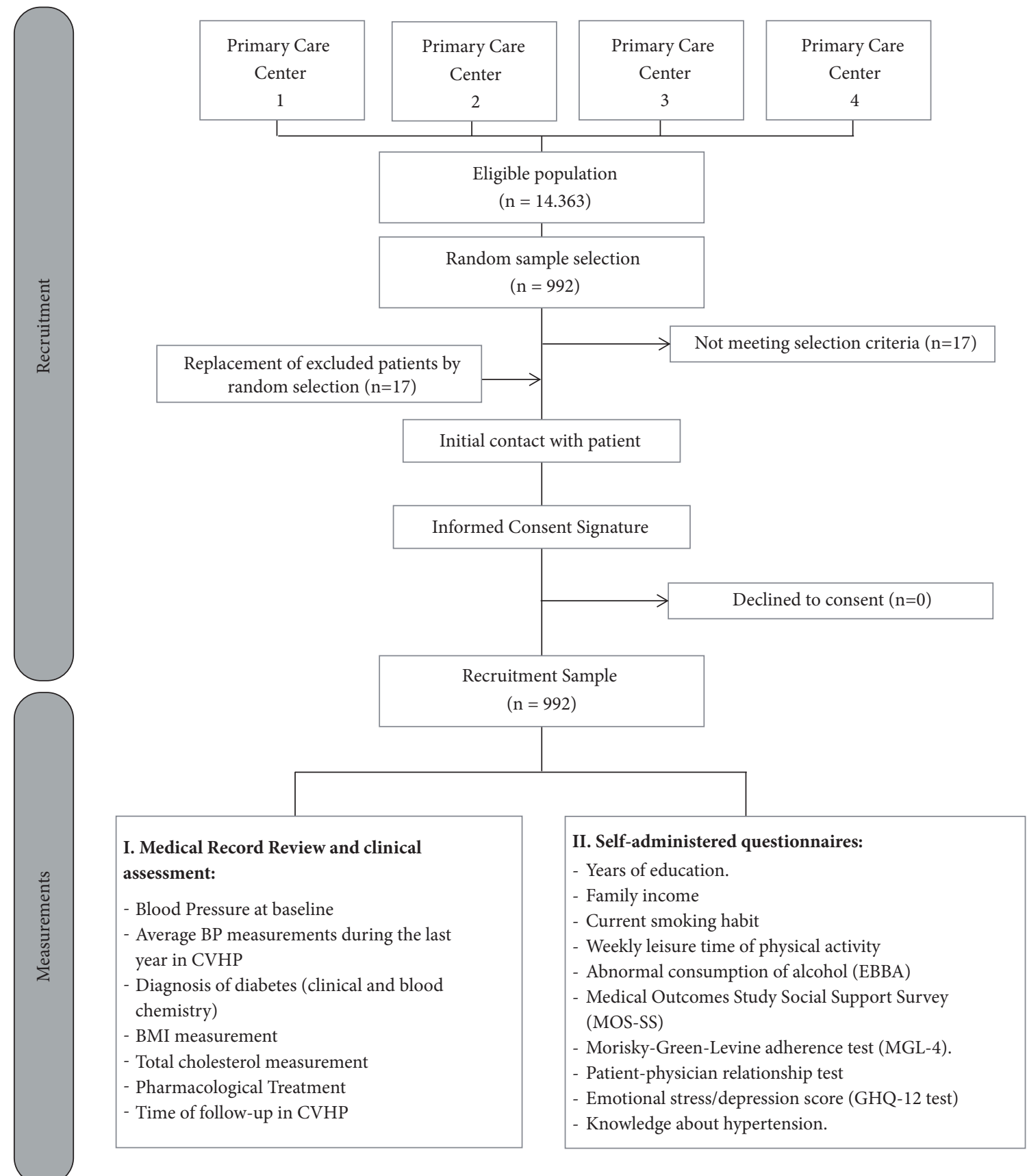

FIGURE 1: Recruitment process and procedures followed after patient's agreement to participate in the study.

person). Low education corresponded to $<$ than 8 years of schooling.

\subsection{Demographic and Psychosocial \\ Characteristics Measurements}

(1) The Morisky-Green-Levine (MGL-4) [15, 16]: a fouritem questionnaire was utilized to assess adherence to $\mathrm{Rx}$. A positive answer $=1$ point; a negative response $=$ 0 point. A patient is considered no adherent with a score of 1 or higher. This test has an alpha Cronbach value of 0.61 for controlled $\mathrm{BP}$ predictive value at 5 years [16]. A sensitivity analysis considering a score of 2 or higher for no adherence was carried out and results are included in Supplemental Table (available here) and discussed in results.

(2) MOS-SS (Medical Outcome Study Social Support Survey) [17], adapted to Spanish and validated for its use in Chilean primary care. It collects multidimensional information about the levels of support that the patient can access. 
(3) Knowledge about hypertension: the following questionnaire was utilized: Is hypertension a life-long condition? Is it possible to control it by diet and medications? Mention two or more organs that may be damaged by high BP. An incorrect answer to any of these questions is indicative of low knowledge.

(4) Emotional Stress/ Depression score: A Chilean validated Spanish version of the GHQ-12 questionnaire was utilized [18]. This test detects and grades the levels of emotional stress and depression.

(5) Patient-physician relations: a version of a Chilean validated questionnaire by Bozzo-Martinez [19] to assess the patient satisfaction with care received at the primary care center was utilized. A score of 71 or less was considered indicative of inadequate patientphysician relation.

(6) Smoking: smokers were defined as those currently smoking at the time of the study.

(7) Use of alcohol: it was evaluated using the EBBA [20] survey (Brief Survey of Abnormal Drinking) to identify alcohol related abnormal behavior, previously validated and of common use in Chile [21].

(8) Physical activity: physically active patients were defined as those who electively exercised for at least 30 minutes three times a week [21].

Using currently accepted clinical guidelines we classified controlled BP as $<140 / 90 \mathrm{mmHg}$, elevated total cholesterol as $\geq 200 \mathrm{mg} / \mathrm{dl}$, and obesity as body mass index $\geq 30 \mathrm{~kg} / \mathrm{m}^{2}$. Multiple antihypertensive drug therapy was defined when patients were prescribed 2 or more drugs.

The Ethic Committee of Research in Humans of the University of Chile Faculty of Medicine approved the study protocol.

2.4. Statistical Analysis. Exploratory analysis for the continuous variables was performed. Categorical variables were expressed as absolute or relative frequencies. Continuous variables were measured as medians (percentile 25 and 75). Differences according to sex, BP control, and adherence for categorical variables were analyzed using the $X^{2}$ test and Mann-Whitney test for continuous variables; $\mathrm{p}$ value $<0.05$ was considered a significant difference.

For uncontrolled BP ( $\geq 140 / 90 \mathrm{mmHg}$ ) odds ratio (OR) with $95 \%$ of confidence intervals was calculated. In Model 1 (unadjusted model) a univariate logistic analysis was performed in reference to uncontrolled BP, which included age (years), baseline systolic and diastolic BP ( $\mathrm{mmHg})$, time of care in the CVHP (years), and BMI $\left(\mathrm{kg} / \mathrm{m}^{2}\right)$ as continuous variables and sex (male), low education $(<8$ years of educations), low family income ( $<80$ US\$ per person/month), inadequate patient-physician relation (score $\leq 71$ ), high emotional stress-depression (score $\geq 7$ ), low social support ( score $<57$ ), low knowledge about hypertension (score $\geq 1$ ), no adherence (score $\geq 1$ ), multiple antihypertensive $\operatorname{RX}(\geq 2$ drug antihypertensive), diabetes mellitus, elevated total cholesterol ( $\geq 200 \mathrm{mg} / \mathrm{dL}$ ), smoking (current), alcohol related abnormal use (score $\geq 2$ ), and sedentary behavior ( $<30 \mathrm{minx} 3 /$ week of leisure physical activity) as dichotomous variables.

In Model 2, all variables that were statistically significant at the $\mathrm{p}<0.05$ level in the unadjusted model were included in the multivariable logistic regression analysis. For no adherence a similar univariate logistic analysis was conducted (Model 1), using in the multivariable logistic regression analysis (Model 2) all the univariate variables that showed statistical significance at the $\mathrm{p}<0.05$ level.

\section{Results}

3.1. Demographic, Socioeconomic, Clinical, and Antihypertensive Therapy and Anthropometric Characteristics. A larger number of women $(n=647,65.2 \%)$ than men $(n=345,34.8 \%)$ were part of this study. Low family income and low education level were documented in 23.0 and $33.2 \%$, respectively. Obesity $\left(\mathrm{BMI} \geq 30 \mathrm{~kg} / \mathrm{m}^{2}\right)$ was found in $58.4 \%$ of patients; higher in women than men (61.1\% versus $53.3 \%, \mathrm{p}=0.019)$, and $37.8 \%$ were diabetics ( $42.3 \%$ men, $35.4 \%$ women, $\mathrm{p}=0.032$ ) (Table 1 ).

The baseline median BP value was 146/91 mmHg. The median BP value corresponding to the last year of care in CVHP at the time of recruitment was $132 / 80 \mathrm{mmHg}$. BP control was achieved in $63.1 \%$ of patients $(66.0 \%$ women versus $57.7 \%$ men, $\mathrm{p}=0.01$ ). Adherence to $\mathrm{Rx}$ was $38.4 \%$, greater in women $(41.1 \%$ versus $33.3 \%, \mathrm{p}=0.016)$. Alcohol abnormal behavior was more frequent in men $(25.5 \%$ versus $7.4 \%, \mathrm{p}<0.001)$; no sex differences were observed in current smoking (25.4\%) and sedentary life style prevalence (83\%). Multiple drug therapy was prescribed in $46.9 \%$ (41.2\% men and $49.6 \%$ women, $\mathrm{p}=0.011$ ).

3.2. Factors Associated with Uncontrolled Blood Pressure. Male sex (OR: 1.73 [95\% CI 1.35 - 2.22]), low family income, high emotional-stress-depression score (OR: 1.32 [95\% CI 1.03 - 1.70]), BMI, no adherence (OR: 1.83 [95\% CI 1.44 2.32]), multiple antihypertensive drug therapy (OR: 1.53 [95\% CI 1.21 - 1.94]), baseline systolic BP value (OR: 1.03 [95\% CI 1.02 - 1.04]), and sedentary life style (OR: 1.61 [95\% CI 1.15 2.25]) were significantly associated with uncontrolled BP in Model 2 (adjusted model). The time of care patients received in the CVHP was not predictive of uncontrolled BP in Model 2 (Table 2).

3.3. Factors Associated with No Adherence to Prescribed Antihypertensive Medications. No adherence was significantly associated with uncontrolled BP (OR: 1.52 [95\% CI 1.22 1.90]), male sex (OR: 1.54 [95\% CI 1.23 - 1.93]), low family income (OR: 1.39 [95\% CI 1.11 - 1.72]), high emotional stressdepression score (OR: 2.15 [95\% CI 1.68 - 2.76]), and low social support in Model 2 (adjusted). The time of care under the CVHP showed no association with no adherence in the univariate logistic analysis (Model 1). In contrast, diabetes mellitus (OR: 0.81 [95\% CI 0.66 - 0.99]) was significantly associated with better adherence (in Models 1 and 2; Table 3).

It is noteworthy the associations of no adherence with uncontrolled BP, male sex, and psychosocial factors did not change after a sensitivity analysis using a no adherence MGL4 score 2 or greater (Supplementary Table). 
TABLE 1: Demographic, socioeconomic, clinical, and antihypertensive therapy and anthropometric characteristics $(\mathrm{n}=992)$.

\begin{tabular}{|c|c|c|c|c|}
\hline Participant Characteristics & $\begin{array}{c}\text { Total } \\
(\mathrm{n}=992)\end{array}$ & $\begin{array}{c}\text { Men } \\
(\mathrm{n}=345)\end{array}$ & $\begin{array}{l}\text { Women } \\
(\mathrm{n}=647)\end{array}$ & p-value \\
\hline \multicolumn{5}{|l|}{ Demographic and socioeconomic characteristics } \\
\hline Age (years) & $56.0(50-61)^{a}$ & $57.0(51-62)^{a}$ & $55.0(49-61)^{a}$ & $<0.01$ \\
\hline Low education ( $<8$ years of education) & $329(33.2)$ & $103(29.9)$ & $226(34.9)$ & 0.11 \\
\hline Low family income ( $<$ US $\$ 80$ per person/month) & $228(23.0)$ & $53(15.4)$ & $175(27.0)$ & $<0.001$ \\
\hline \multicolumn{5}{|l|}{ Psychosocial variables } \\
\hline Inadequate patient -physician relation ${ }^{* 874}$ & $202(23.1)$ & $63(21.0)$ & $139(24.2)$ & 0.28 \\
\hline High emotional stress-depression score & $258(26.0)$ & $59(17.1)$ & $199(30.8)$ & $<0.001$ \\
\hline Low social support & $338(34.1)$ & $88(25.5)$ & $250(38.6)$ & $<0.001$ \\
\hline Low family Cohesion & $366(36.9)$ & $95(27.5)$ & $271(41.9)$ & $<0.001$ \\
\hline Self-perception of health (poor-very poor) & $177(17.8)$ & $48(13.9)$ & $129(19.9)$ & 0.018 \\
\hline Knowledge about hypertension & $542(54.6)$ & $190(55.1)$ & $352(54.4)$ & 0.84 \\
\hline \multicolumn{5}{|l|}{ Blood Pressure } \\
\hline Systolic blood pressure (mmHg) & $132(123.3-143.2)^{\mathrm{a}}$ & $133(124.3-144.9)^{\mathrm{a}}$ & $131(123.0-142.7)^{\mathrm{a}}$ & 0.033 \\
\hline Diastolic blood pressure (mmHg) & $80(75.0-86.7)^{a}$ & $82.0(76.7-80.0)^{a}$ & $80.0(75.0-86.5)^{\mathrm{a}}$ & 0.006 \\
\hline Blood pressure control ( $\mathrm{BP}<140 / 90 \mathrm{mmHg})$ & $626(63.1)$ & $199(57.7)$ & $427(66.0)$ & 0.010 \\
\hline Baseline Systolic blood pressure (mmHg) & $146(140-160)^{\text {a }}$ & $150(140-160)^{a}$ & $144(140-160)^{\mathrm{a}}$ & 0.134 \\
\hline Baseline Diastolic blood pressure (mmHg) & $91(90-100)^{\mathrm{a}}$ & $92.0(90-100)^{\mathrm{a}}$ & $90(90.9-100)^{\mathrm{a}}$ & 0.270 \\
\hline Time of care in CVHP (years) & $7.0(4.0-10.7)^{\mathrm{a}}$ & $6.3(3.5-8.9)^{\mathrm{a}}$ & $7.5(4.3-11.4)^{\mathrm{a}}$ & $<0.001$ \\
\hline \multicolumn{5}{|l|}{ Clinical variables } \\
\hline Diabetes mellitus (clinical diagnosis) & $375(37.8)$ & $146(42.3)$ & $229(35.4)$ & 0.032 \\
\hline Total Cholesterol $(\mathrm{mg} / \mathrm{dL})^{* 865}$ & $200(172-230)^{a}$ & $193.0(166-227)^{a}$ & $203(177-232)^{a}$ & 0.005 \\
\hline Elevated total cholesterol $(\geq 200 \mathrm{mg} / \mathrm{dL})^{* 865}$ & $439(50.8)$ & $138(45.7)$ & $201(53.5)$ & 0.031 \\
\hline \multicolumn{5}{|l|}{ Antihypertensive treatment variables } \\
\hline Multiple antihypertensive drug therapy ( $\geq 2$ drugs) & $463(46.9)$ & $142(41.2)$ & $321(49.6)$ & 0.011 \\
\hline Adherence to pharmacological therapy & $381(38.4)$ & $115(33.3)$ & $266(41.1)$ & 0.016 \\
\hline \multicolumn{5}{|l|}{ Anthropometrics variables } \\
\hline Weight $(\mathrm{Kg})$ & $78.0(68.4-89.7)^{\mathrm{a}}$ & $84.2(76.0-96.1)^{\mathrm{a}}$ & $75.0(66.0-84.9)^{a}$ & $<0.001$ \\
\hline Height $(\mathrm{m})$ & $1.57(1.52-1.64)^{\mathrm{a}}$ & $1.67(1.63-1.71)^{\mathrm{a}}$ & $1.53(1.49-1.57)^{\mathrm{a}}$ & $<0.001$ \\
\hline Body mass index $\left(\mathrm{Kg} / \mathrm{m}^{2}\right)$ & $31.2(28.0-34.9)^{\mathrm{a}}$ & $30.6(27.8-33.9)^{\mathrm{a}}$ & $31.5(28.2-35.7)^{\mathrm{a}}$ & 0.001 \\
\hline Obesity (BMI $\left.\geq 30 \mathrm{Kg} / \mathrm{m}^{2}\right)$ & $579(58.4)$ & $184(53.3)$ & $395(61.1)$ & 0.019 \\
\hline \multicolumn{5}{|l|}{ Lifestyle habits } \\
\hline Smoking (Current smoker) & $253(25.4)$ & $87(25.2)$ & $165(25.5)$ & 0.88 \\
\hline Alcohol related abnormal behavior & $136(13.7)$ & $88(25.5)$ & $48(7.4)$ & $<0.001$ \\
\hline Sedentary ( $<30 \mathrm{~min} x 3 /$ week of leisure physical activity) & $823(83.0)$ & $284(82.3)$ & $539(83.3)$ & 0.82 \\
\hline
\end{tabular}

${ }^{a}$ Median values (percentile 25-75) or $\mathrm{n}(\%) ;{ }^{*}$ number of patients in whom measurement was performed. All values included in Table 1 were determined at the time of recruitment to the study with the exception of baseline BP measurement indicative of values at the time of referral of patients to the CVHP. Systolic and diastolic $\mathrm{BP}$ and $\mathrm{BP}$ control at time of recruitment considers the average of the values in the last year at time of recruitment.

\section{Discussion}

The BP control (63.1\%) observed in this sample of hypertensive patients enrolled in the CVHP compares favorably with results published in many high-income countries [22-25]. In addition, our results contrast with a 2004 study in a Chilean Southern region urban population that showed BP control in $30.7 \%$ of 1,838 patients under antihypertensive therapy [26], and the 2010 Chilean National Health survey that reported BP control in $45.3 \%$ of hypertensive patients who informed to be under treatment [21]. More recently, a study from a CVHP cohort showed BP control of 59.7\% [10]. The adherence to antihypertensive drug therapy in our study was only $38.4 \%$, but there is no reliable information of adherence in Chilean hypertensive patients for comparison with results prior to the CVHP. The influences of adherence in the results of our study are illustrated by the significant association found of uncontrolled hypertension to no adherence, consistent with many previous observations [3, 5, 9, 22]. Although the use of the MGL-4 questionnaire may have possibly overestimated the actual no adherence, it is also conceivable that the comprehensive multidisciplinary support provided 
TABLE 2: Multivariable adjusted odds ratio for uncontrolled BP $(\geq 140 / 90 \mathrm{~mm} / \mathrm{Hg})$ in hypertensive patients followed in the Cardiovascular Health Program.

\begin{tabular}{|c|c|c|c|c|}
\hline & $\begin{array}{c}\mathrm{BP}<140 / 90 \mathrm{mmHg} \\
\mathrm{n}=626 \\
\mathrm{n}(\%)\end{array}$ & $\begin{array}{c}\mathrm{BP} \geq 140 / 90 \mathrm{mmHg} \\
\mathrm{n}=366 \\
\mathrm{n}(\%)\end{array}$ & $\begin{array}{c}\text { Model } 1 \\
\text { Unadjusted } \\
\text { Odds Ratio } \\
(\mathrm{CI} 95 \%)\end{array}$ & $\begin{array}{c}\text { Model } 2 \\
\text { Adjusted } \\
\text { Odds Ratio* } \\
(\text { CI } 95 \%)\end{array}$ \\
\hline \multicolumn{5}{|l|}{ Demographic and socioeconomic characteristic } \\
\hline Age (years) & $56(49-61)^{\mathrm{a}}$ & $58(50-63)^{a} \ddagger$ & $1.03(1.01-1.04) \ddagger$ & $1.01(0.99-1.03)$ \\
\hline Male sex & $199(31.8)$ & $146(39.9) \ddagger$ & $1.56(1.30-1.86) \ddagger$ & $1.73(1.35-2.22) \ddagger$ \\
\hline Low education ( $<8$ years of education) & $191(30.5)$ & $138(37.7) \dagger$ & $1.58(1.31-1.90) \ddagger$ & $1.21(0.94-1.56)$ \\
\hline Low family income ( $<$ US\$80 per person/month) & $189(30.2)$ & $124(34.0)$ & $1.19(0.99-1.44)$ & $1.44(1.13-1.84) \ddagger$ \\
\hline \multicolumn{5}{|l|}{ Psychosocial variables } \\
\hline Inadequate patient -physician relation & $179(31.1)$ & $100(33.4)$ & $1.20(0.99-1.47)$ & $1.07(0.84-1.37)$ \\
\hline High emotional stress-depression score & $153(24.4)$ & $105(28.7)$ & $1.29(1.06-1.57) \dagger$ & $1.32(1.03-1.70) \dagger$ \\
\hline Low social support & $221(33.7)$ & $127(34.7)$ & $1.15(0.96-1.38)$ & $1.08(0.85-1.37)$ \\
\hline Low knowledge about hypertension & $333(53.2)$ & $209(57.1)$ & $1.15(0.97-1.38)$ & $1.17(0.93-1.47)$ \\
\hline \multicolumn{5}{|l|}{ Antihypertensive treatment variables } \\
\hline No adherence & $360(57.5)$ & $251(68.6) \dagger$ & $1.67(1.39-2.00) \ddagger$ & $1.83(1.44-2.32) \ddagger$ \\
\hline Multiple antihypertensive RX & $255(40.7)$ & $280(56.8) \ddagger$ & $1.73(1.45-2.07) \ddagger$ & $1.53(1.21-1.94) \ddagger$ \\
\hline Time of care in CVHP (years) & $6.6(4.0-9.9)^{\mathrm{a}}$ & $7.6(3.9-11.5)^{\mathrm{a}} \dagger$ & $1.03(1.01-1.05) \ddagger$ & $1.00(0.97-1.02)$ \\
\hline Systolic blood pressure baseline in CVHP & $140(134.5-152)^{\mathrm{a}}$ & $150(140-164.2)^{a} \ddagger$ & $1.03(1.03-1.04) \ddagger$ & $1.03(1.02-1.04) \ddagger$ \\
\hline Diastolic blood pressure baseline in CVHP & $90(90-100)^{\mathrm{a}}$ & $96(90-100)^{a} \ddagger$ & $1.02(1.01-1.03) \ddagger$ & $1.00(0.99-1.01)$ \\
\hline \multicolumn{5}{|l|}{ Anthropometrics and clinical variables } \\
\hline Diabetes mellitus & $248(39.6)$ & $127(34.7)$ & $0.88(0.74-1.06)$ & $0.87(0.69-1.09)$ \\
\hline Elevated total cholesterol $(\geq 200 \mathrm{mg} / \mathrm{dL})$ & $289(50.3)$ & $150(51.5)$ & $1.01(0.83-1.22)$ & $1.07(0.86-1.34)$ \\
\hline $\mathrm{BMI}\left(\mathrm{Kg} / \mathrm{m}^{2}\right)$ & $30.8(27.8-34.2)^{\mathrm{a}}$ & $32.1(28.5-36.1)^{\mathrm{a}}+$ & $1.05(1.03-1.06) \ddagger$ & $1.04(1.02-1.07) \ddagger$ \\
\hline \multicolumn{5}{|l|}{ Lifestyle habits } \\
\hline Smoking (current smoker) & $170(27.2)$ & $82(22.4)$ & $0.74(0.60-0.90) \ddagger$ & $1.00(0.78-1.30)$ \\
\hline Alcohol related abnormal behavior & $69(11.0)$ & $67(18.3) \ddagger$ & $1.69(1.32-2.15) \ddagger$ & $1.23(0.89-1.71)$ \\
\hline Sedentary & $505(80.7)$ & $318(86.9) \ddagger$ & $1.60(1.25-2.05) \ddagger$ & $1.61(1.15-2.25) \ddagger$ \\
\hline
\end{tabular}

${ }^{a}$ Median values (percentile 25-75); $\dagger \mathrm{p}<0.05, \ddagger \mathrm{p}<0.01 . *$ OR adjusted for all the variables that were significant at the $\mathrm{p}<0.05$ level in unadjusted model: age (years), systolic and diastolic blood pressure baseline in CVHP (mmHg), and time of follow-up in CVHP (years) and BMI $\left(\mathrm{Kg} / \mathrm{m}^{2}\right)$ as continuous variables. Sex (male), low education ( $<8$ years of educations), high emotional stress-depression (score $\geq 7$ ), no adherence (score $\geq 1$ ), multiple antihypertensive RX ( $\geq 2$ drug antihypertensive), alcohol related abnormal (score $\geq 2)$, smoking (current), and sedentary ( $<30 \mathrm{minx} 3 /$ week of leisure physical activity) as dichotomous variables.

the CVHP may have partially offset the negative influence of low antihypertensive drug therapy adherence in our results. The lack of association in the time patients received care in the CVHP and uncontrolled BP suggests that the beneficial influence of the program in achieving BP control may begin early and do not fade with a longer permanence of patients in it. It is of note that our findings are similar to those of the ALLHAT trial in USA that documented BP control in $56.2 \%$ of the patients after 1 year of management [25] through a similar free universal comprehensive management as in the CVHP. In this study Hispanics had 20\% greater odds of achieving BP control than Non-Hispanic Whites, reversing dramatically previously documented trends between these racial/ethnic groups in USA [24].

The significant association of male sex, low family income, high emotional-stress-depression, no adherence to treatment $(\mathrm{Rx})$, high $\mathrm{BMI}$, multiple antihypertensive drug therapy, baseline systolic BP value, and sedentary life style with uncontrolled BP in our study is in agreement with previous studies $[3,4,6,7,9]$. Also we found a significant association of uncontrolled BP with low social support and male sex, factors that were also significantly predictive of no adherence. Conflictive results in the association of sex with BP control in treated hypertensive patients have been published [27, 28]. However, a study done in 5 European countries, Canada, and USA that included 73,446 patients showed that BP control in hypertensive patients was 2-fold higher in women compared with men in Spain, Italy, Canada, and the United States [29]. It is of note that none of these studies analyzed the association of BP control and adherence, or with socioeconomic and psychosocial factors. To the best of our knowledge, no previous study has documented that no adherence to $\mathrm{Rx}$ in men may contribute to the reported differences in BP control with women. The inferior $\mathrm{BP}$ control in men may be likely related to their larger no adherence, which may be also a factor partially involved in 
TABLE 3: Multivariable adjusted odds ratio for no adherence risk to antihypertensive in hypertensive patients followed in the Cardiovascular Health Program.

\begin{tabular}{|c|c|c|c|c|}
\hline & $\begin{array}{c}\text { Adherence } \\
\mathrm{n}=381 \\
\mathrm{n}(\%)\end{array}$ & $\begin{array}{c}\text { No Adherence } \\
\text { n= 611 } \\
n(\%)\end{array}$ & $\begin{array}{c}\text { Model } 1 \\
\text { Unadjusted } \\
\text { Odds Ratio } \\
(\mathrm{CI} 95 \%)\end{array}$ & $\begin{array}{c}\text { Model } 2 \\
\text { Adjusted } \\
\text { Odds Ratio* } \\
(\text { CI } 95 \%)\end{array}$ \\
\hline \multicolumn{5}{|l|}{ Demographic and socioeconomic characteristic } \\
\hline Age & $56(50-61)^{\mathrm{a}}$ & $55(49-61)^{\mathrm{a}}$ & $0.99(0.98-1.00)$ & $0.99(0.98-1.00)$ \\
\hline Male sex & $115(30.2)$ & $230(37.6) \dagger$ & $1.47(1.22-1.76) \ddagger$ & $1.54(1.23-1.93) \ddagger$ \\
\hline Low education ( $<8$ years of education) & $119(31.2)$ & $210(34.4)$ & $1.12(0.93-1.35)$ & $1.06(0.85-1.32)$ \\
\hline Low family income ( $<$ US\$80 per person month) & $68(17.8)$ & $160(26.2) \ddagger$ & $1.66(1.35-2.06) \ddagger$ & $1.39(1.11-1.72) \ddagger$ \\
\hline \multicolumn{5}{|l|}{ Psychosocial variables } \\
\hline Inadequate patient -physician relation & $95(28.1)$ & $184(34.3) \dagger$ & $1.33(1.09-1.63) \ddagger$ & $1.04(0.84-1.29)$ \\
\hline High emotional stress-depression score & $76(19.9)$ & $182(29.8) \ddagger$ & $1.84(1.49-2.26) \ddagger$ & $2.15(1.68-2.76) \ddagger$ \\
\hline Low social support & $113(29.7)$ & $225(36.8) \dagger$ & $1.44(1.19-1.73) \ddagger$ & $1.34(1.08-1.66) \ddagger$ \\
\hline Low Knowledge about hypertension & $200(52.5)$ & $342(56.0)$ & $1.08(0.91-1.28)$ & $0.98(0.81-1.21)$ \\
\hline \multicolumn{5}{|l|}{ Antihypertensive treatment variables } \\
\hline Uncontrolled BP ( $\geq 140 / 90$ mmHg) & $160(42.0)$ & $305(49.9) \dagger$ & $1.67(1.39-2.00) \ddagger$ & $1.52(1.22-1.90) \ddagger$ \\
\hline Multiple antihypertensive RX & $197(51.7)$ & $266(43.5) \dagger$ & $0.81(0.68-0.96) \dagger$ & $0.92(0.75-1.13)$ \\
\hline Time of care in CVHP (years) & $6.9(3.9-11.9)^{\mathrm{a}}$ & $6.7(3.9-10.2)^{\mathrm{a}}$ & $0.98(0.96-1.00)$ & $0.98(0.95-1.00)$ \\
\hline Systolic blood pressure baseline in CVHP & $150(140-160)^{a}$ & $145(140-160)^{\mathrm{a}}$ & $1.00(0.99-1.00)$ & $1.00(0.99-1.00)$ \\
\hline Diastolic blood pressure baseline in CVHP & $94(90-100)$ & $90(90-100)$ & $0.99(0.98-1.00)$ & $1.00(0.99-1.00)$ \\
\hline \multicolumn{5}{|l|}{ Anthropometrics and clinical variables } \\
\hline Diabetes mellitus & $156(40.9)$ & $219(35.8)$ & $0.80(0.67-0.95) \dagger$ & $0.81(0.66-0.99) \dagger$ \\
\hline Elevated total cholesterol $(\geq 200 \mathrm{mg} / \mathrm{dL})$ & $160(48.3)$ & $273(52.7)$ & $1.23(1.02-1.48) \dagger$ & $1.26(1.04-1.54) \dagger$ \\
\hline BMI $\left(\mathrm{Kg} / \mathrm{m}^{2}\right)$ & $31(28-35)^{\mathrm{a}}$ & $31(27-35)^{a}$ & $1.00(0.99-1.02)$ & $1.00(0.98-1.02)$ \\
\hline \multicolumn{5}{|l|}{ Lifestyle habits } \\
\hline Smoking (Current smoker) & $97(25.5)$ & $156(25.5)$ & $0.98(0.81-1.19)$ & $0.98(0.78-1.22)$ \\
\hline Alcohol related abnormal behavior & $39(10.2)$ & $97(15.9) \dagger$ & $1.55(1.19-2.01) \ddagger$ & $1.18(0.86-1.60)$ \\
\hline Sedentary & $310(81.4)$ & $513(84.0)$ & $1.16(0.92-1.45)$ & $0.98(0.75-1.29)$ \\
\hline
\end{tabular}

${ }^{\mathrm{a}}$ Median values (percentile $25-75$ ); $\dagger \mathrm{p}<0.05, \neq \mathrm{p}<0.01$. $*$ OR adjusted for all the variables that were significant at the $\mathrm{p}<0.05$ level in unadjusted model: sex (male), low family income $<$ US $\$ 80$ per person/month), inadequate patient-physician relation (score $\leq 71$ ), high emotional stress-depression (score $\geq 7$ ), low social support (score $<57$ ), uncontrolled BP $(\geq 140 / 90 \mathrm{mmHg}$ ), multiple antihypertensive RX ( $\geq 2$ drug antihypertensive), diabetes, elevate total cholesterol $(\geq$ $200 \mathrm{mg} / \mathrm{dL}$ ), and alcohol related abnormal (score $\geq 2$ ) as dichotomous variables.

their underrepresentation in our study. It is also conceivable that the comprehensive multidisciplinary services provided by the CVHP may contribute in reducing patients negative expectations about therapies (the nocebo [30] effects that induce a reduction of their efficacy and or tolerance) and eventually lead to an improvement in compliance. In addition, conflicts with their work activities are a well-known factor limiting access of men to health care, issue that is a challenge for the Chilean health care services. Nevertheless, the proportion of men in our study (women/ men $=1.87$ ) showed a slight increase when compared to the ratio found in a previous study (2.15) from a similar population followed in the CVHP [10], possibly reflecting a favorable trend in the recruitment of men to the program (please see Table 4).

The association of low family income, high emotional stress/depression, and low social support in our study underscored the significance of socioeconomic and psychosocial factors in BP control and adherence [6, 8, 31-34]. We also found that low income was associated with no adherence, despite patient's unrestricted free access to health care and drug therapy but consistent with previous observations and indicative of the complex causal pathways and welldocumented relations of socioeconomic position and health $[6,8,31]$. Our finding that adherence to $(\mathrm{Rx})$ appeared not to be hampered but favored by the association with diabetes has been noted by others in a study in hypertensive patients receiving multiple drug therapy due to comorbidities [35]. As discussed by these authors, hypertensive patients with associated comorbidities may be more aware of being at a higher risk and then more willing to follow the recommended drug therapy. It is of note that we found no differences in BP control between diabetics and nondiabetics, in contrast to a previous study from a CVHP population that showed worse BP control in diabetics [10] (Table 4). Since adherence was only measured in our current and more recent study it is uncertain if this difference also reflected adherence improvements in diabetics that plausibly may have occurred in the interim. These changes are significant achievements in 
TABLE 4: Comparative values of BP control by sex, presence of diabetes, and adherence in the evaluation of two different groups from the CVHP.

\begin{tabular}{|c|c|c|c|c|}
\hline & $\begin{array}{c}2009-2010[10] \\
n=1,194\end{array}$ & p-value & $\begin{array}{c}2011-2014 \\
n=992\end{array}$ & p-value \\
\hline \multicolumn{5}{|l|}{ Sex } \\
\hline Women & $69.1 \%$ & \multirow{2}{*}{$<0.01$} & $65.2 \%$ & \multirow{2}{*}{$<0.01$} \\
\hline Men & $31.9 \%$ & & $34.8 \%$ & \\
\hline \multicolumn{5}{|l|}{ BP according to sex } \\
\hline BP control in women & $63.7 \%$ & \multirow{2}{*}{$<0.01$} & $66.0 \%$ & \multirow{2}{*}{0.01} \\
\hline BP control in men & $52.4 \%$ & & $57.7 \%$ & \\
\hline \multicolumn{5}{|l|}{ BP control and diabetes } \\
\hline BP control in diabetics & $53.2 \% *$ & \multirow{2}{*}{$<0.01$} & $66.1 \% *$ & \multirow{2}{*}{0.12} \\
\hline BP control in nondiabetics & $62.4 \%$ & & $61.3 \%$ & \\
\hline \multicolumn{5}{|l|}{ Adherence and diabetes } \\
\hline Adherence in diabetics & - & & $41.6 \%$ & \multirow{2}{*}{0.10} \\
\hline Adherence in nondiabetics & - & & $36.5 \%$ & \\
\hline
\end{tabular}

* $\mathrm{p}<0.01$, difference between groups.

a population with such alarming rates of obesity and diabetes (58.4 and $37.5 \%$, respectively).

Our study has several limitations. The underrepresentation of men as compared to women (women/men=1.87) in this cohort is a persistent problem in the CVHP, although an improvement trend may be already occurring (Table 4). As discussed, it has been attributed to conflicts with labor activities of men in Chile, but also probably reflective of the greater no adherence to therapy found in men. It is uncertain if the results of this study are applicable to patients that stayed in the program for less than 1 year or were older than 64 years of age (not included in this study). Although hypertensive patients with cardiovascular comorbidities or undergoing hemodialysis were referred to a second level of care (specialist) and not followed in the CVHP, it is unlikely that their small proportion could have influenced our results (3.17\% of the eligible population). Finally, physical activity was assessed throughout a questionnaire used in the 2010 Chilean National Health Survey [21] that only counted time spend in leisure type of exercise and did not consider physical activity involved in transportation or work (bicycle, walking), common in the study population. This may explain the high number of sedentary subjects found in our study (86.9\%).

\section{Conclusions}

Our study emphasizes the importance of socioeconomic and psychosocial factors influencing BP control and adherence in hypertensive patients in a developing society. The underrepresentation of hypertensive men enrolled in the CVHP, their worse BP control, and adherence represents an important challenge to address in this program. Nevertheless, our findings underscore an important historical improvement in BP control in Chile, a developing country in a stage of advanced socioeconomic transition, that we attribute to the implementation of a comprehensive, multidisciplinary approach in the management of hypertensive patients (CVHP) providing free of copayments medical care, and counseling in lifestyle modifying changes, with results in BP control similar to some of those reported in high-income societies [25, 35, 36]. These favorable results were highlighted by the results noted in the hypertensive diabetic group, a particularly vulnerable population, with CVHP historical improvement in BP control and similar adherence as nondiabetic hypertensive. The lack of influence of time spend by patients in the program to achieve favorable BP results provides additional support to the consideration of programs similar to the CVHP in the developing world.

\section{Disclosure}

The opinions contained in this work are exclusively from the authors and do not represent necessarily those from University of Chile School of Medicine, University of California, San Diego, California, and Institutional Review Board of Sharp Health Care, San Diego, California. A presentation of the content of this work was made at the 2017 American Heart Association QOCR meeting, April 2-3, 2017, Arlington, Virginia.

\section{Conflicts of Interest}

The authors declare that they have no conflicts of interest.

\section{Authors' Contributions}

Daniela Sandoval contributed in the study design, data collection, data analysis, and manuscript writing. Carolina Nazzal contributed in the study design, data analysis, and manuscript writing. Tomás Romero contributed in the study planning and design, data analysis, manuscript writing, and obtaining partial research funding.

\section{Acknowledgments}

This research has been partially financed by a Grant from Fundación Araucaria Foundation, San Diego, California. 


\section{Supplementary Materials}

Supplementary Table: multivariable adjusted odds ratio for no adherence risk to antihypertensive drug therapy using Morisky-Green-Levine-4 items questionnaire in patients followed in the Cardiovascular Health Program. Association with outcomes using two different definitions of no adherence according to the score $(>1$ versus $>2$ ). (Supplementary Materials)

\section{References}

[1] P. M. Kearney, M. Whelton, K. Reynolds, P. Muntner, P. K. Whelton, and J. He, "Global burden of hypertension: analysis of worldwide data," The Lancet, vol. 365, no. 9455, pp. 217-223, 2005.

[2] World Heart Federation, Cardiovascular Disease Report, State of the Heart, 2010, http://www.paho.org/col/index.php?option= com_docman\&amp;view=download\&amp;alias=649-state-ofthe-heart-cvd-report-240910\&amp;category_slug=publicaciones-ops-oms-colombia\&amp;Itemid $=688$.

[3] A. V. Chobanian, G. L. Bakris, H. R. Black et al., "The seventh report of the joint national committee on prevention, detection, evaluation, and treatment of high blood pressure: the JNC 7 report," The Journal of the American Medical Association, vol. 289, no. 19, pp. 2560-2572, 2003.

[4] I. Hajjar and T. A. Kotchen, "Trends in prevalence, awareness, treatment, and control of hypertension in the United States, 1988-2000," Journal of the American Medical Association, vol. 290, no. 2, pp. 199-206, 2003.

[5] "The Task Force for the management of arterial hypertension of the European Society of Hypertension (ESH) and of the European Society of Cardiology (ESC)," in 2013 ESH/ESC Guidelines for the management of arterial hypertension, vol. 34, pp. 2159-2219, European Heart Journal, 2013.

[6] S. Basu and C. Millet, "Determinants of Prevalence, Diagnosis, Treatment, and Control in the WHO SAGE Study," Hypertension, vol. 62, no. 1, pp. 18-26, 2013.

[7] D. E. Bloom, E. T. Cafiero, E. Jané-Llopis et al., The Global Economic Burden of Noncommunicable Diseases, World Economic Forum, 2011.

[8] M. Marmot, "Social determinants of health inequalities," The Lancet, vol. 365, no. 9464, pp. 1099-1104, 2005.

[9] C. Bourgault, M. Sénécal, M. Brisson, M. A. Marentette, and J.-P. Grégoire, "Persistence and discontinuation patterns of antihypertensive therapy among newly treated patients: A population-based study, Journal of Human Hypertension, vol. 19, no. 8, pp. 607-613, 2005.

[10] D. Sandoval, M. Bravo, E. Koch et al., "Overcoming Barriers in the Management of Hypertension: The Experience of the Cardiovascular Health Program in Chilean Primary Health Care Centers," International Journal of Hypertension, vol. 2012, pp. 1-8, 2012.

[11] 2016, http://www.worldbank.com.

[12] T. J. Bossert and T. Leisewitz, "Innovation and change in the chilean health system," The New England Journal of Medicine, vol. 374, no. 1, pp. 1-5, 2016.

[13] Ministry of Health, 2016, http://www.supersalud.gob.cl/normativa/668/articles-13722_recurso_1.pdf.

[14] Ministry of Health, Area of Analysis, Department of Statistics and Health Information, 2012.
[15] D. E. Morisky, L. W. Green, and D. M. Levine, "Concurrent and predictive validity of a self-reported measure of medication adherence," Medical Care, vol. 24, no. 1, pp. 67-74, 1986.

[16] D. E. Morisky, A. Ang, M. Krousel-Wood, and H. J. Ward, "Predictive validity of a medication adherence measure in an outpatient setting," The Journal of Clinical Hypertension, vol. 10, no. 5, pp. 348-354, 2008.

[17] C. D. Sherbourne and A. L. Stewart, "The MOS social support survey," Social Science \& Medicine, vol. 32, no. 6, pp. 705-714, 1991.

[18] D. P. Golberg and V. F. Hillier, "A scale version of the General Health Questionnaire," Psychological Medicine, vol. 9, no. 1, pp. 139-145, 1979.

[19] G. Bozzo, B. Martínez, P. Sepúlveda et al., "Development and validation of a survey for patients satisfaction in primary care clinics," Revista Medica De Chile, vol. 123, pp. 1160-1164, 1995.

[20] E. Florenzano, N. Horwitz, M. Penna, and M. Valdés, "alidation of an abbreviated scale for detection of abnormal drinking behavior (E.B.B.A) (Escala Breve para la detección del Beber Anormal)," in Mental Health and Primary Health Care subjects (Temas de Salud Mental y Atención Primaria de Salud.), pp. 185193, Facultad de Medicina, Universidad de Chile, 1991.

[21] Ministry of Health (Ministerio de Salud, MINSAL), National Health Survey, Chile, Vol. 1. Santiago, 2009-2010. http://web .minsal.cl/search/node/Encuesta\%20MINSAL.

[22] T. G. Pickering, "Why are we doing so badly with the control of hypertension? Poor compliance is only part of the story," The Journal of Clinical Hypertension, vol. 3, no. 3, pp. 179-182, 2001.

[23] A. L. Valderrama, C. Gillespie, and C. Mercado, "Racial/Ethnic Disparities in the Awareness, Treatment and Control of Hypertension- United States," in Centers for Disease Control and Prevention, vol. 62, 354, MMWR, 352 edition, 2013, http://www .cdc.gov/nchs/nhanes/response_rates_cps.htm.

[24] A. V. Chobanian, "The hypertension paradox - More uncontrolled disease despite improved therapy," The New England Journal of Medicine, vol. 361, no. 9, pp. 848-887, 2009.

[25] K. L. Margolis, L. B. Piller, C. E. Ford et al., "Blood pressure control in hispanics in the antihypertensive and lipid-lowering treatment to prevent heart attack trial," Hypertension, vol. 50, no. 5, pp. 854-861, 2007.

[26] E. Fasce, I. Campos, P. Ibáñez et al., "Trends in prevalence, awareness, treatment and control of hypertension in urban communities in Chile," Journal of Hypertension, vol. 25, no. 9, pp. 1807-1811, 2007.

[27] K. L. Ong, A. W. K. Tso, K. S. L. Lam, and B. M. Y. Cheung, "Gender difference in blood pressure control and cardiovascular risk factors in Americans with diagnosed hypertension," Hypertension, vol. 51, no. 4, pp. 1142-1148, 2008.

[28] S. Keyhani, J. V. Scobie, P. L. Hebert, and M. A. McLaughlin, "Gender disparities in blood pressure control and cardiovascular care in a national sample of ambulatory care visits," Hypertension, vol. 51, no. 4, pp. 1149-1155, 2008.

[29] K. Wolf-Maier, R. S. Cooper, H. Kramer et al., "Hypertension treatment and control in five european countries, Canada, and the United States," Hypertension, vol. 43, no. 1, pp. 10-17, 2004.

[30] L. Colloca and D. Finniss, "Nocebo effects, patient-clinician communication, and therapeutic outcomes," Journal of the American Medical Association, vol. 307, no. 6, pp. 567-568, 2012.

[31] C. M. Eze-Nliam, B. D. Thombs, B. B. Lima, C. G. Smith, and R. C. Ziegelstein, "The association of depression with adherence to antihypertensive medications: A systematic review," Journal of Hypertension, vol. 28, no. 9, pp. 1785-1795, 2010. 
[32] A. V. Diez Roux, "Persistent social patterning of cardiovascular risk: Rethinking the familiar," Circulation, vol. 111, no. 23, pp. 3020-3021, 2005.

[33] C. Bane, C. M. Hughes, and J. C. McElnay, "The impact of depressive symptoms and psychosocial factors on medication adherence in cardiovascular disease," Patient Education and Counseling, vol. 60, no. 2, pp. 187-193, 2006.

[34] E.-L. Wu, I.-C. Chien, C.-H. Lin, Y.-J. Chou, and P. Chou, "Increased risk of hypertension in patients with major depressive disorder: A population-based study," Journal of Psychosomatic Research, vol. 73, no. 3, pp. 169-174, 2012.

[35] G. Mazzaglia, E. Ambrosioni, M. Alacqua et al., "Adherence to antihypertensive medications and cardiovascular morbidity among newly diagnosed hypertensive patients," Circulation, vol. 120, no. 16, pp. 1598-1605, 2009.

[36] M. G. Jaffe, G. A. Lee, J. D. Young, S. Sidney, and A. S. Go, "Improved blood pressure control associated with a large-scale hypertension program," The Journal of the American Medical Association, vol. 310, no. 7, pp. 699-705, 2013. 


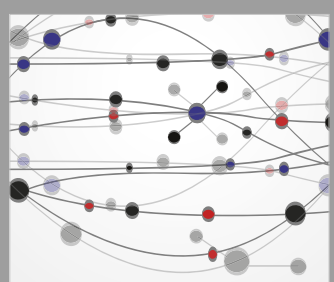

The Scientific World Journal
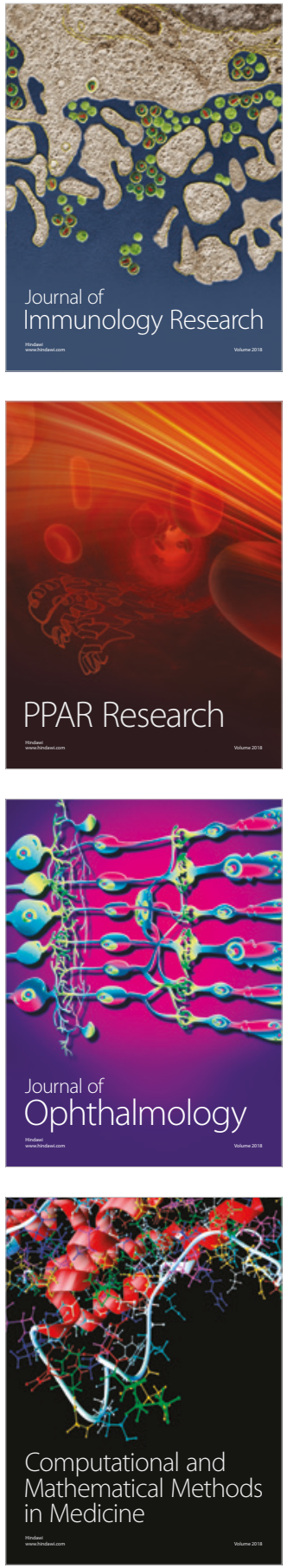

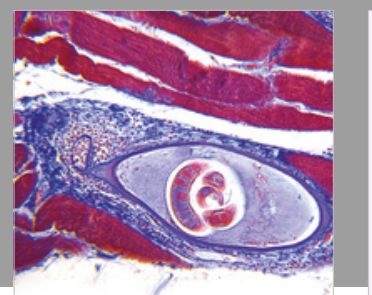

Gastroenterology Research and Practice

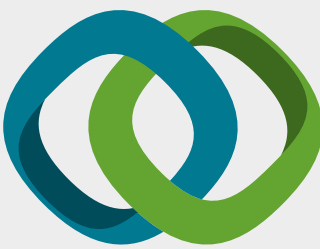

\section{Hindawi}

Submit your manuscripts at

www.hindawi.com
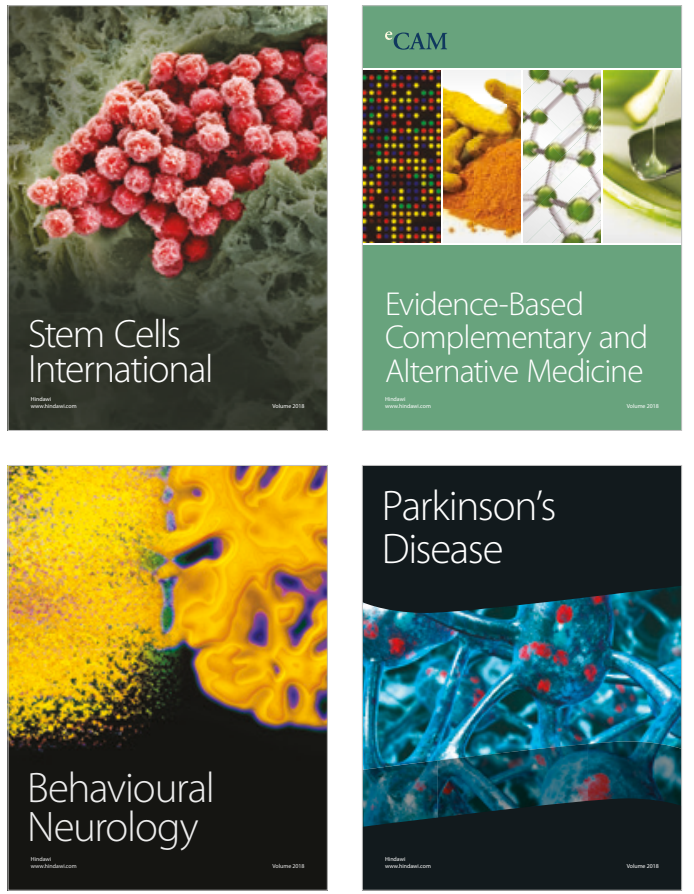

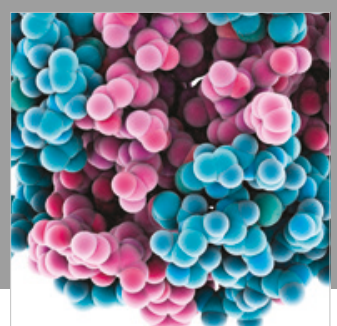

ournal of

Diabetes Research

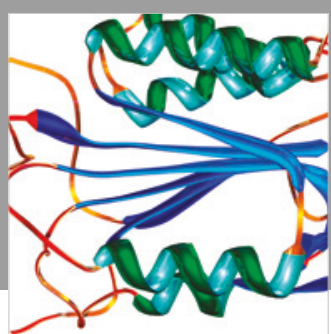

Disease Markers
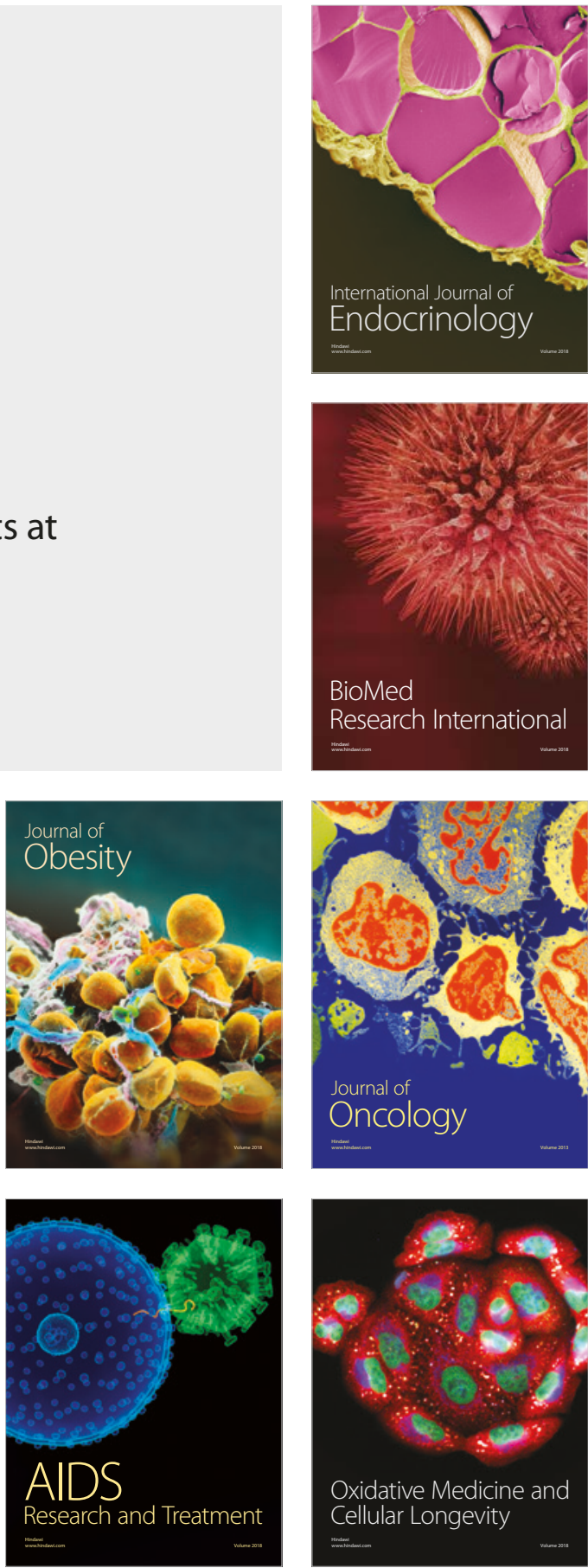